\title{
Reliability and Lifetime Prediction of Remote Phosphor Plates in Solid-State Lighting Applications Using Accelerated Degradation Testing
}

\author{
M. YAZDAN MEHR, ${ }^{1,2}$ W.D. VAN DRIEL, ${ }^{2,3}$ and G.Q. ZHANG ${ }^{2,4}$ \\ 1.-Material Innovation Institute (M2i), Delft, The Netherlands. 2.-EEMCS Faculty, Delft \\ University of Technology, Delft, The Netherlands. 3.-Philips Lighting, Eindhoven, The Nether- \\ lands. 4.—e-mail: G.Q.Zhang@tudelft.nl
}

\begin{abstract}
A methodology, based on accelerated degradation testing, is developed to predict the lifetime of remote phosphor plates used in solid-state lighting (SSL) applications. Both thermal stress and light intensity are used to accelerate degradation reaction in remote phosphor plates. A reliability model, based on the Eyring relationship, is also developed in which both acceleration factors (light intensity and temperature) are incorporated. Results show that the developed methodology leads to a significant decay of the luminous flux, correlated colour temperature (CCT) and chromatic properties of phosphor plates within a practically reasonable period of time. The combination of developed acceleration testing and a generalized Eyring equation-based reliability model is a very promising methodology which can be applied in the SSL industry.
\end{abstract}

Key words: LED, remote phosphor, light intensity, thermal ageing

\section{INTRODUCTION}

Light emitting diodes (LEDs), made by combining phosphor with blue light sources, are the most commercially available solid state light (SSL) sources. ${ }^{1-10}$ In this type of LED, the phosphor is either coated on the chip or mixed with the lens disc. ${ }^{11-22}$ The spatial distribution of phosphor in white LED lamps strongly influences the colour uniformity and the efficiency of the light source. In proximate phosphor distributions, the phosphor is located in close proximity to the semiconductor chip, while in the remote phosphor configuration, there is a distance between the phosphor layer and the chip. Schematics of different possible phosphor distribution configurations are shown in Fig. 1.

SSL devices are normally based on a blue chip, combined with yellow phosphor, and are typically in the range of $4500-8000 \mathrm{~K}$ correlated colour temperature (CCT). Recent development strategies are based on the production of white LEDs in the lower

(Received June 23, 2015; accepted October 1, 2015;

published online November 5, 2015)
CCT range (2700-4500 K), since lumens per watt values of LEDs in this range exceed those in the incandescent lamps. ${ }^{7,8}$ The main aim of reliability studies in the LED industry is to analyze the system reliability data for SSL luminaires and components and to determine the time-to-failure of the components. Recent publications ${ }^{9,10}$ provide recommendations for assessment of the lifetime of luminaire products. These reports highlight the proper use of LM-80 and TM21 standards which are wellapproved methods in reliability testing. LM-80 provides a procedure to measure the lumen maintenance of LED light sources, while TM-21 provides a method to project long-term lumen maintenance of the LED light sources using LM-80 data. ${ }^{11,12}$

Even though there have been many technological breakthroughs in the SSL industry, there are still numerous reliability issues, not yet completely known and understood. Besides, a major issue in reliability studies of LEDs is that most available degradation testing techniques are not fast enough to be applied in such a fast growing industry. The objective of the present study is to develop a high 

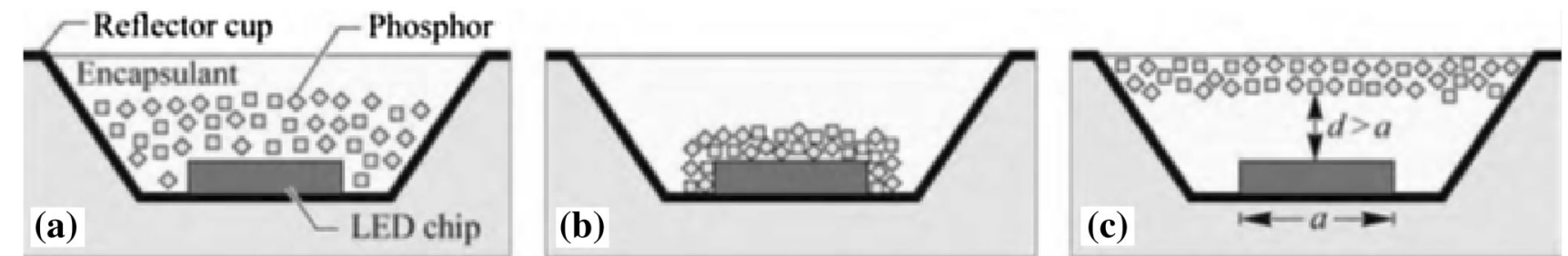

Fig. 1. Schematics of (a) proximate phosphor distributions, (b) conformal proximate phosphor distributions, and (c) remote phosphor distribution. ${ }^{4}$

accelerated stress testing (HAST) set-up to study the effects of both blue light intensity and the thermal stress on the lifetime and the kinetics of aging phosphor plates used in SSL luminaires. This work is a significant step forward and an improvement in our previously applied accelerated test methodology, ${ }^{22}$ where the only applied stress factor was thermal stress. Application of both thermal stress and light intensity in a HAST set-up is expected to make the kinetics of degradation much faster. There are many papers regarding the reliability of LED systems ${ }^{13-21}$ under thermal stress; however, there is limited information available about the effects of combined blue light intensity and thermal stress on the ageing and the reliability of remote phosphors. In this study, the effects of both stress factors, applied in the HAST set-up, are studied. A generalized Eyring equation is also used to correlate the data from the HAST set-up with the lifetime and the reliability of phosphor plates.

\section{EXPERIMENTAL SET-UP}

Remote phosphor plates $3 \mathrm{~mm}$ thick with a CCT of $4000 \mathrm{~K}$ and colour rending index (CRI) of 80 are used in this study. Remote phosphor plates used in this study consist of polycarbonate plates $(3 \mathrm{~mm}$ thick) as the substrate and a phosphor coating layer. In this study, luminescent powder mix is made of yttrium aluminum garnet (YAG) powder with $3.3 \%$ Ce content and $1.5 \%$ nitride red phosphor, doped with CaSN-Eu. A coating layer on the polyethylene terephthalate (PET) film, consisting of inorganic luminescent material, is transferred to polycarbonate sheet material by a hot press laminating process.

Figure 2 shows an overview picture of the HAST system including all components. The core of the HAST consists of a blue light source with a wavelength of $450 \mathrm{~nm}$ and a working surface. The blue light sources are Philips modules; with each module containing 18 high-power LED packages.

Samples are placed on the working surface and are directly aged under blue light radiation. The working surface is a hot plate and absorptive filters are placed between the samples and the hot plate in order to prevent the reflection of light by the surface of the hot plate. The hot plate is constantly calibrated by an infrared (IR) camera. The temperature on the surface of the hot plate is perfectly homogenous, with the difference not being more than $2^{\circ} \mathrm{C}$ all over the plate. The blue light source (Fig. 2) is composed of a mechanical assembly that holds the light source at a desired distance from the hot plate. Because of technical limitation it was not possible to change the current of the blue Light source. So, in order to change the light intensity, the distance between the samples and the blue light source is changed. The homogeneity of the light source across the samples was checked using a photometer at different distances and times.

Three temperatures of $80^{\circ} \mathrm{C}, 100^{\circ} \mathrm{C}$, and $120^{\circ} \mathrm{C}$ are used and samples are aged up to $3000 \mathrm{~h}$. The blue light is radiated on the sample with different light intensities of $825 \mathrm{~W} / \mathrm{m}^{2}, 3300 \mathrm{~W} / \mathrm{m}^{2}$, and $13,200 \mathrm{~W} / \mathrm{m}^{2}$. The change in the spectral power distribution (SPD) is used as a measure to monitor the optical degradation of remote phosphors.

Optical properties of photo-aged plates, i.e. the luminous flux depreciation and the CCT of plates, were studied at room temperature using an integrated sphere. In addition, colour shifting in the aged specimens was also monitored.

\section{RELIABILITY MODEL}

The reliability model for the lifetime assessment of remote phosphor plates is based on an exponential luminous decay equation, where the $\Phi$ can be calculated as ${ }^{13}$

$$
\phi(t)=\beta \exp (-\alpha t)
$$

with $\ddot{O}(t)$ being the lumen output, $\alpha$ is the degradation reaction rate or depreciation rate parameter, $t$ is the ageing time and $\beta$ is a pre-factor. When lumen output, $\Phi$, is equal to $70 \%, t$ is time-to-failure. ${ }^{12}$ In the HAST experiments, where the light intensity is also used as an extra acceleration factor, the Eyring relationship, given below, is a more appropriate equation ${ }^{12}$ :

$$
R=\gamma_{0}(I)^{n} \exp \left(\frac{-E_{a}}{\mathrm{KT}}\right)
$$

where $R$ is the reaction rate, $\gamma_{0}$ is the pre-exponential factor, $I$ is the intensity of blue light, $n$ is the constant factor, $E_{a}$ is the activation energy $(\mathrm{eV})$ of the degradation reaction, $K$ is the Boltzmann gas constant $(\mathrm{eV} / \mathrm{K})$, and $T$ is the absolute temperature (K). The ageing temperatures of the hot plate were adjusted as $80^{\circ} \mathrm{C}, 100^{\circ} \mathrm{C}$, and $120^{\circ} \mathrm{C}$. However, by radiation of light the temperature of phosphor 


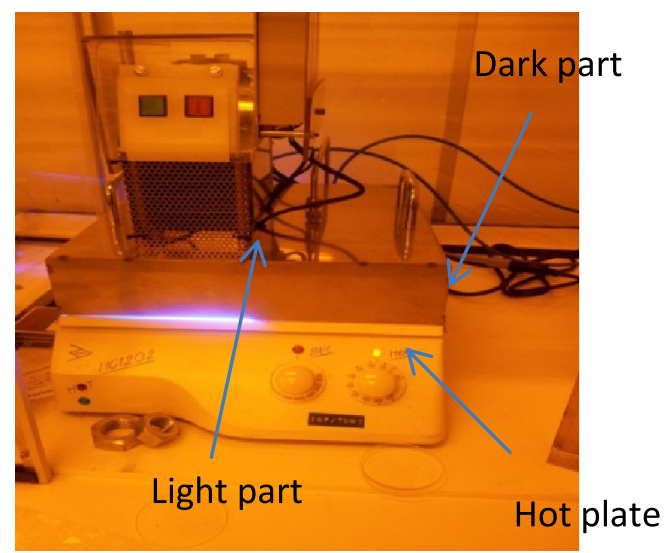

(a)

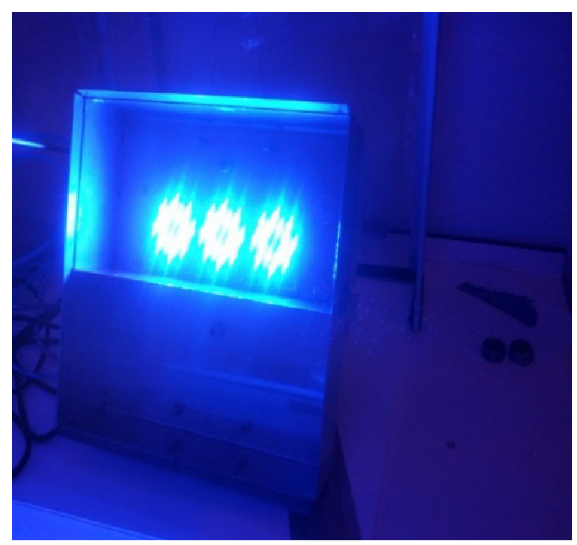

(c)

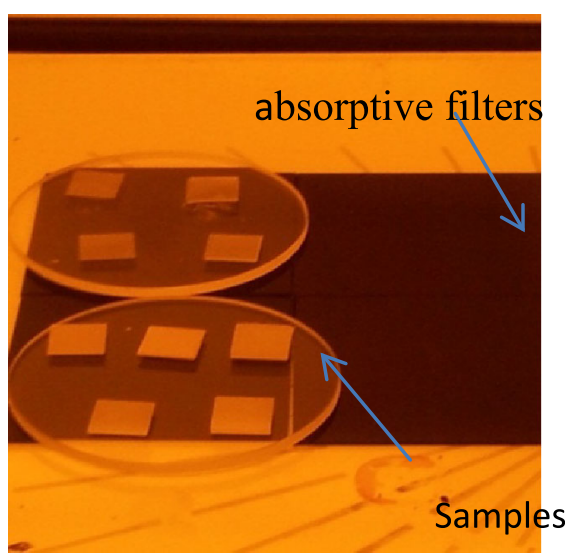

(b)

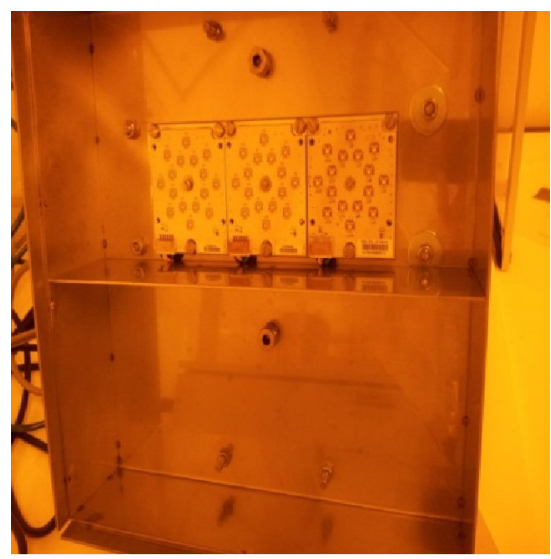

(d)

Fig. 2. High accelerated stress testing (HAST) set up, with (a) frontal view in off state (top left); (b) samples on the absorptive filter (top right); (c) the blue LED light source (bottom left); and d) frontal view in off state (bottom right).

plates increases up to $2^{\circ} \mathrm{C}, 10^{\circ} \mathrm{C}$, and $20^{\circ} \mathrm{C}$ for $825 \mathrm{~W} / \mathrm{m}^{2}, 3300 \mathrm{~W} / \mathrm{m}^{2}$, and $13,200 \mathrm{~W} / \mathrm{m}^{2}$ intensities, respectively. The increase of the temperature by radiation of light is measured by a thermometer with an accuracy of $\pm 0.5^{\circ} \mathrm{C}$. This temperature increase is taken into consideration in our calculations.

\section{RESULTS}

\section{Effect of Light Intensity on the Kinetics of Degradation}

The evolution of the normalized flux intensity and, therefore, the ageing kinetics of degradation of phosphor plates are shown in Fig. 3.

Obviously, the degradation rate shows a significant dependency on the stress light intensity; the higher the light intensity, the faster the degradation kinetics and, therefore, the higher the lumen depreciation. One can also see that by increasing the temperature, the lumen depreciation takes place with faster kinetics. The main effect of light with different intensities is increasing the temperature of the phosphor. The real temperatures of plates were considered in calculating the lumen depreciation and, consequently, the reaction rate. It is clearly seen in Fig. 3 that the degradation follows an Arrhenius law: by increasing the temperature, the rate of ageing increases.

The activation energy of the degradation reaction in phosphor plates is calculated using the Arrhenius equation (Eq. 3). In order to calculate the activation energy of the degradation reaction, the natural logarithm of the reaction rates, obtained from Eq. 2, is plotted against the inverse of the absolute temperature. The activation energy of the degradation reaction can, obviously, be obtained from the slope of this curve (see Fig. 4). The activation energy, $E_{a}$, can be obtained from the slope of the curves. One can see that the activation energies in all ageing tests are the same and the difference in the kinetics is due to the light intensity (intercept).

As is already explained, based on the Alliance for Solid-State Illumination Systems and Technologies (ASSIST) standard, the lifetime of LEDs is defined as time to reach $70 \%$ of the initial lumen output. ${ }^{10}$ The reaction rate, $a$, assumed to be constant for each temperature, is calculated as follows: 
(a)

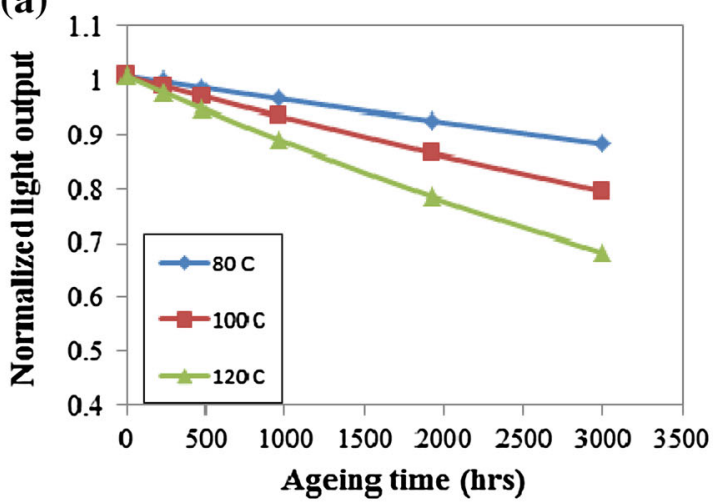

(b)

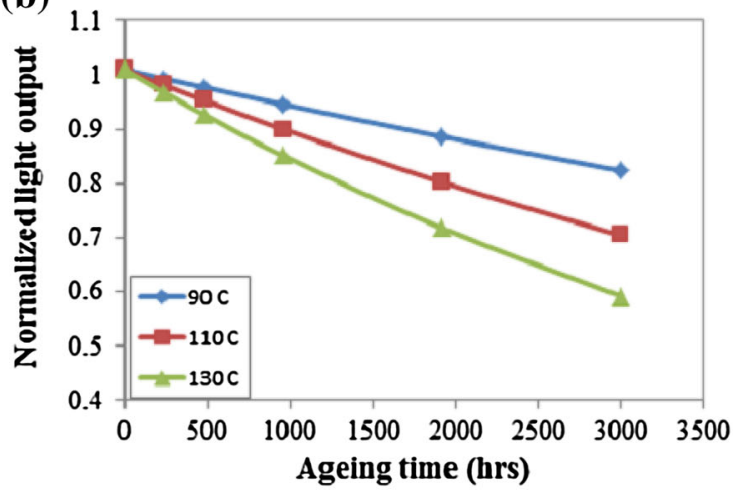

(c)

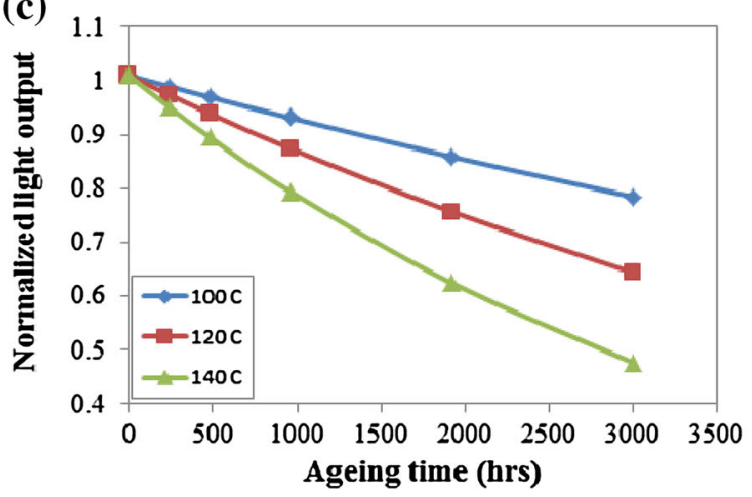

Fig. 3. Normalized light output of remote phosphor plates at different radiation intensities, (a) $825 \mathrm{~W} / \mathrm{m}^{2}$, (b) $3300 \mathrm{~W} / \mathrm{m}^{2}$ and (c) $13,200 \mathrm{~W} / \mathrm{m}^{2}$. Note the correction for temperature increase due to the higher intensities.

$$
a(T)=\frac{-\ln [\phi(t)]}{t}
$$

where $t$ is the time for $30 \%$ lumen depreciation and $\ddot{O}$ is the luminous flux (equal to $70 \%$ ). The reaction rates of all three temperatures and three light intensities are shown in Table I. It is important to mention again that the temperatures in Table I are the applied temperatures and the real temperature of the phosphor plates is corrected by $+2^{\circ} \mathrm{C},+10^{\circ} \mathrm{C}$, and $+20^{\circ} \mathrm{C}$ for $825 \mathrm{~W} / \mathrm{m}^{2}, 3300 \mathrm{~W} / \mathrm{m}^{2}$, and $13,200 \mathrm{~W} /$ $\mathrm{m}^{2}$ intensities, respectively.

The direction of the change in the chromaticity coordinates of remote phosphor photo-thermal ageing is illustrated in Fig. 5. As is shown in this figure, the light source is getting yellowish, indicating that not only the light output efficiency, but also the colour of the emitted light, is degraded. One can also notice that by increasing the light intensity, the kinetics of ageing increases. Thermal-stress tests have also some significant effects on the CCT. The variation of CCT during ageing at high temperature stress testing for remote phosphor plates is shown in Table II. It is obvious that by increasing the thermal ageing time, the CCT decreases.

\section{Package Luminous Efficiency}

One of the key advantages of LED-based lighting sources is their high luminous efficacy. In recent years, Philips Lumileds made LEDs available with a luminous efficacy of 100-150 lumens per watt $(\mathrm{lm} /$ W). The emission spectra of the reference blue LED, and blue-pumped white LED with yellow phosphor are shown in Fig. 6. The measured emission spectra can be seen as blue emission from an LED chip together with yellow emission from phosphor.

The power conversion efficiencies of the package are calculated using the equation given here:

$$
\eta_{\mathrm{LCE}}=\left(\frac{\phi_{\text {output }}}{\phi_{\text {input }}}\right)
$$

where $\phi_{\text {output }}$ is output power of the yellow component and $\phi_{\text {input }}$ is the output power between the blue LED reference emission (without phosphor) and the blue component of the aged remote phosphor, as summarized in Fig. 7. Clearly, the drop in the conversion efficiency has a significant dependence on the stress temperature and the light intensity level. By increasing both the ageing temperature and the light intensity, a 
(a)

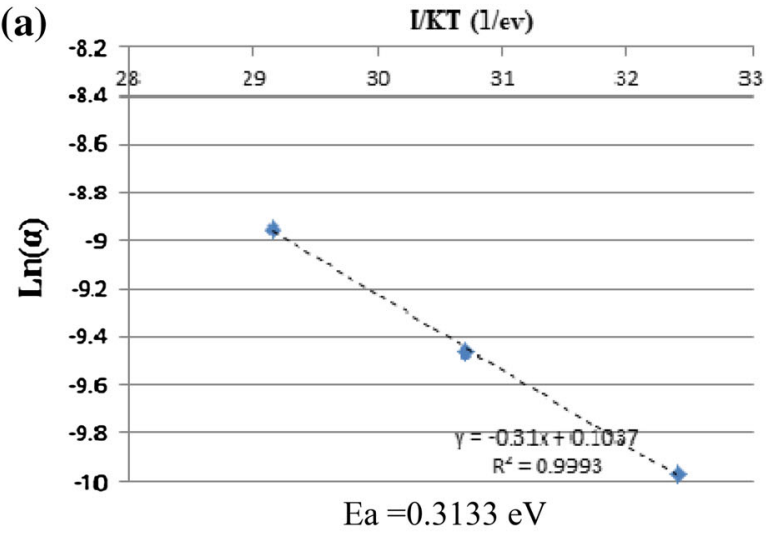

(b)

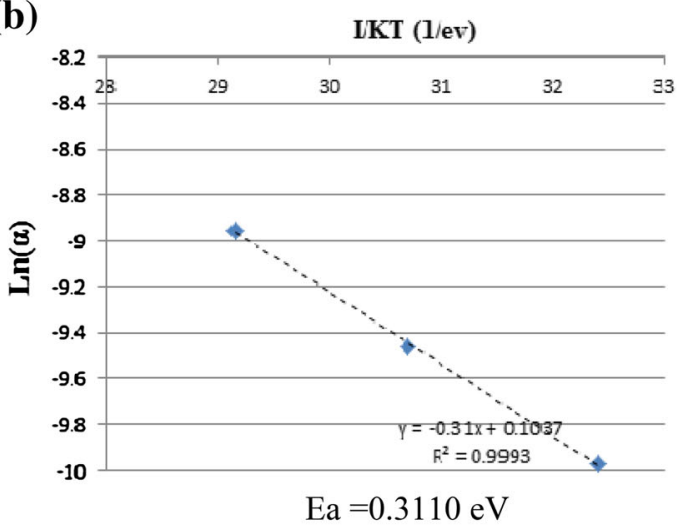

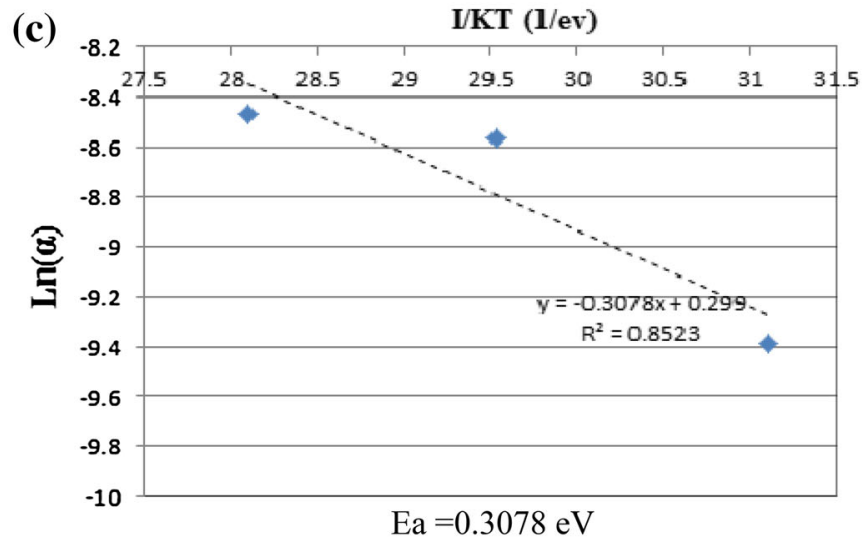

Fig. 4. Plot of In (a) versus E/KT for remote phosphor (a) $825 \mathrm{~W} / \mathrm{m}^{2}$, (b) $3300 \mathrm{~W} / \mathrm{m}^{2}$ and (c) $13,200 \mathrm{~W} / \mathrm{m}^{2}$.

Table I. Reaction rate a for remote phosphor plate at temperatures of $80-120^{\circ} \mathrm{C}$

\begin{tabular}{|c|c|c|c|}
\hline $\begin{array}{l}\text { Light intensity } \\
\left(\mathrm{W} / \mathbf{m}^{2}\right)\end{array}$ & 825 & 3300 & 13,200 \\
\hline Temperature $\left({ }^{\circ} \mathrm{C}\right)$ & & & \\
\hline 80 & $\begin{array}{l}4.68 \mathrm{E}-5 \\
78 \mathrm{E}-5\end{array}$ & $\begin{array}{l}5.7 \mathrm{E}-5 \\
96 \mathrm{E}-5\end{array}$ & $\begin{array}{l}8.4 \mathrm{E}-5 \\
19 \mathrm{E}-5\end{array}$ \\
\hline 100 & $\begin{array}{c}7.8 \mathrm{E}-5 \\
129 \mathrm{E}-4\end{array}$ & $\begin{array}{r}9.6 \mathrm{E}-5 \\
1.54 \mathrm{E}-4\end{array}$ & $\begin{array}{l}1.9 \mathrm{E}-5 \\
2.1 \mathrm{E}-4\end{array}$ \\
\hline
\end{tabular}

more significant drop in the conversion efficiency is expected. The reduction of conversion efficiency is because of discoloration of BPA-PC and a reduction of the conversion efficiencies of the phosphors (with time).

\section{Effect of Light Intensity on the Acceleration of Ageing Test}

Using a generalized Eyring equation, ${ }^{12}$ the acceleration factor of the tests at different stresses can be calculated. Acceleration factor is a measure of how much faster the test is performed at a certain testing condition, compared to normal behavior at real working conditions. Obviously, the higher the acceleration factor, the faster and the more efficient (in terms of needed time for the experiment) the experiments. This factor is defined by the following equation:

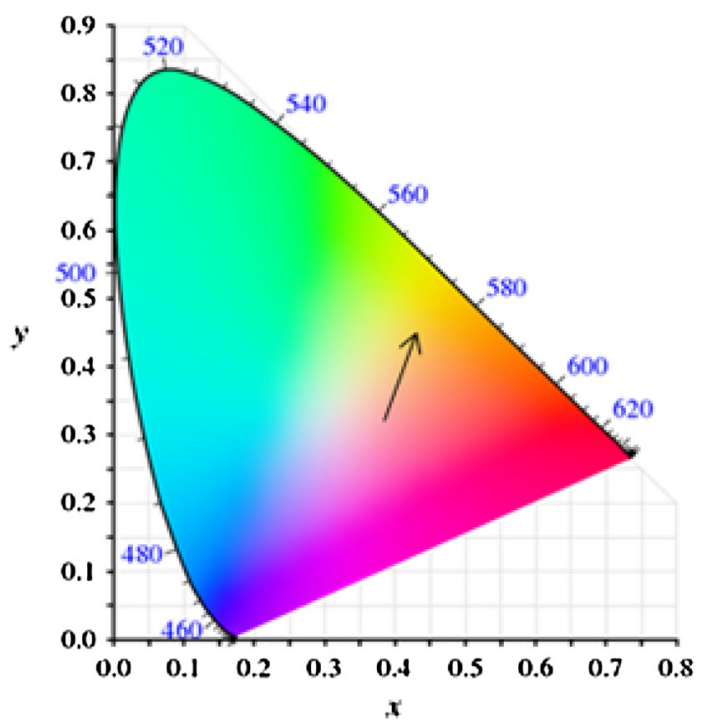

Fig. 5. The variation of chromatic chromaticity for $13,200 \mathrm{~W} / \mathrm{m}^{2}$ at $120^{\circ} \mathrm{C}$.

$$
A f=\left(\frac{I}{I_{0}}\right)^{n} \exp \left(\frac{E_{a}}{K}\left(\frac{1}{T_{\text {reference }}}-\frac{1}{T_{\text {test }}}\right)\right)
$$


Table II. CCT for remote phosphor plates at temperatures of $80-120^{\circ} \mathrm{C}$ after $3000 \mathrm{~h}$ of ageing

\begin{tabular}{|c|c|c|c|}
\hline Light intensity $\left(\mathrm{W} / \mathrm{m}^{2}\right)$ & 825 & 3300 & 13,200 \\
\hline \multicolumn{4}{|l|}{ Temperature $\left({ }^{\circ} \mathrm{C}\right)$} \\
\hline 80 & 4410 & 4370 & 4300 \\
\hline 100 & 4120 & 4000 & 3900 \\
\hline 120 & 4050 & 3900 & 3720 \\
\hline
\end{tabular}

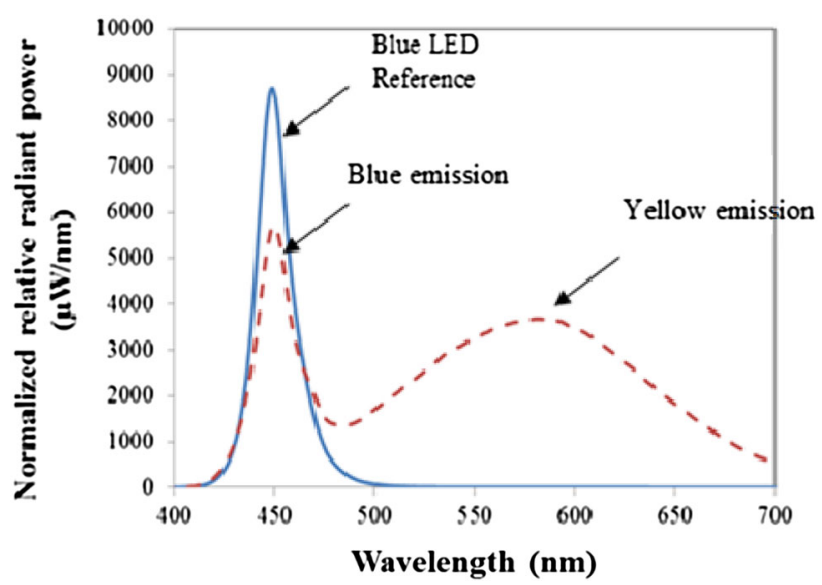

Fig. 6. Emission spectra of reference blue LED, and blue-pumped white LED with yellow phosphor. where $T_{\text {reference }}$ is the reference temperature, which is assumed to be $80^{\circ} \mathrm{C}$ and closer to reality, and $T_{\text {test }}$ is the testing temperature, $I$ is the intensity of blue light which is $13,200 \mathrm{~W} / \mathrm{m}^{2}$ and $3300 \mathrm{~W} / \mathrm{m}^{2}$, and $I_{0}$ is the reference light intensity which is considered to be $850 \mathrm{~W} / \mathrm{m}^{2}$. The acceleration factors of remote phosphor at ageing temperatures of $80-120^{\circ} \mathrm{C}$ with radiation of light with intensities $825 \mathrm{~W} / \mathrm{m}^{2}$, $3300 \mathrm{~W} / \mathrm{m}^{2}$, and $13,300 \mathrm{~W} / \mathrm{m}^{2}$ are given in Fig. 8 .

The radiation of light accelerates the kinetics of ageing of remote phosphor. The increase in the acceleration factor by the radiation of light indicates the effect of light intensity (see Eq. 5). Using Eq. 5, the power factor, $n$, is found to be equal to 0.2 . The acceleration factors of remote phosphor at an ageing temperature of $120^{\circ} \mathrm{C}$ with radiations of $825 \mathrm{~W} / \mathrm{m}^{2}$, $3300 \mathrm{~W} / \mathrm{m}^{2}$, and $13,300 \mathrm{~W} / \mathrm{m}^{2}$ in light and dark experiments are given in Fig. 9. The radiation of light obviously accelerates the ageing of remote phosphor by a factor 1.01, 1.2 and 1.9 for blue light radiations of $825 \mathrm{~W} / \mathrm{m}^{2}, 3300 \mathrm{~W} / \mathrm{m}^{2}$ and $13,200 \mathrm{~W} / \mathrm{m}^{2}$, respectively. The increase in acceleration factor by radiation of light indicates the effect of light intensity (see Eq. 5).

\section{Effect of Light Intensity on the Time-to-Fail- ure of Remote Phosphor}

The temperature of phosphor during service can increase up to $100^{\circ} \mathrm{C} .^{8,9}$ However, in this paper, the
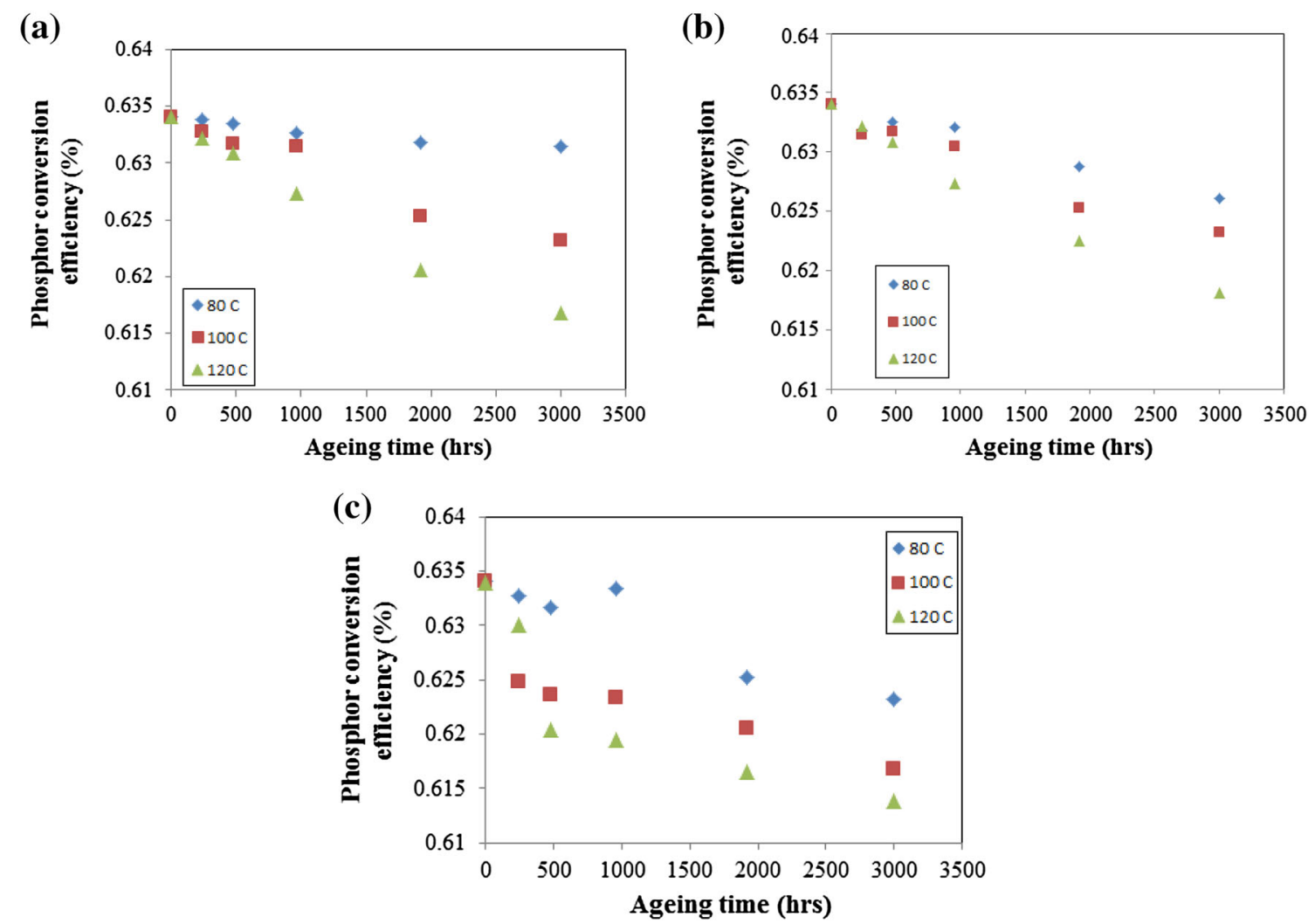

Fig. 7. Conversion efficiency of remote phosphor plates at different radiation intensities, (a) $825 \mathrm{~W} / \mathrm{m}^{2}$, (b) $3300 \mathrm{~W} / \mathrm{m}^{2}$ and (c) $13,200 \mathrm{~W} / \mathrm{m}^{2}$. 


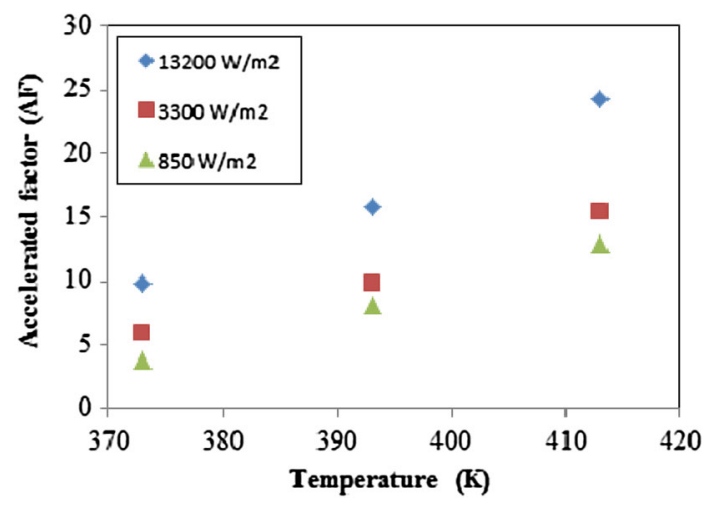

Fig. 8. Acceleration factor of photo-thermal-aged phosphor at $120^{\circ} \mathrm{C}$.

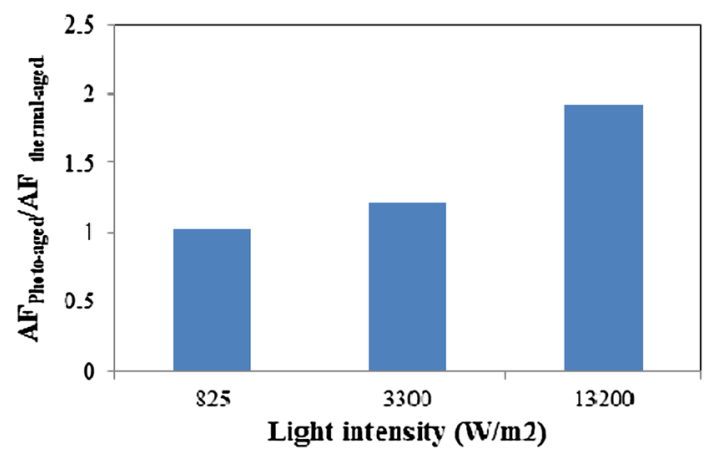

Fig. 9. Acceleration factor of thermal and photo-thermal-aged phosphor at $120^{\circ} \mathrm{C}$.

mentioned reference temperature $\left(80^{\circ} \mathrm{C}\right)$ is more an average value over the whole year. The kinetics of lumen depreciation to $30 \%$ of its initial value can be calculated using Eq. 1, equating $\phi$ to 0.7, knowing that $a$ can be obtained from Eq. 2. Figure 10 illustrates the time-to-failure (70\% lumen decay) of remote phosphors calculated at different temperatures for the photo-thermal ageing where the ageing temperature was $120^{\circ} \mathrm{C}$. Data for the reference sample (thermally aged at $120^{\circ} \mathrm{C}$ without light radiation) is added for the sake of comparison. ${ }^{21}$ It is shown that the lifetime, defined as $30 \%$ lumen depreciation at $40^{\circ} \mathrm{C}$, is around $35 \mathrm{kh}$ for the lowest energy power, which has almost the same lifetime as thermally-aged phosphor. The lifetime of the phosphors with higher power energy is $25 \mathrm{kh}$.

\section{DISCUSSION AND CONCLUSIONS}

The placement and arrangement of phosphors with respect to the chip is an absolutely critical issue for the efficiency of white LEDs. One of the major drawbacks of a proximate conformal phosphor configuration is the temperature increase in the phosphor, which can affect the phosphor efficiencies. Remote phosphors are an alternative to overcome this, but at the expense of more material and, perhaps, some limitations in the design flexi-

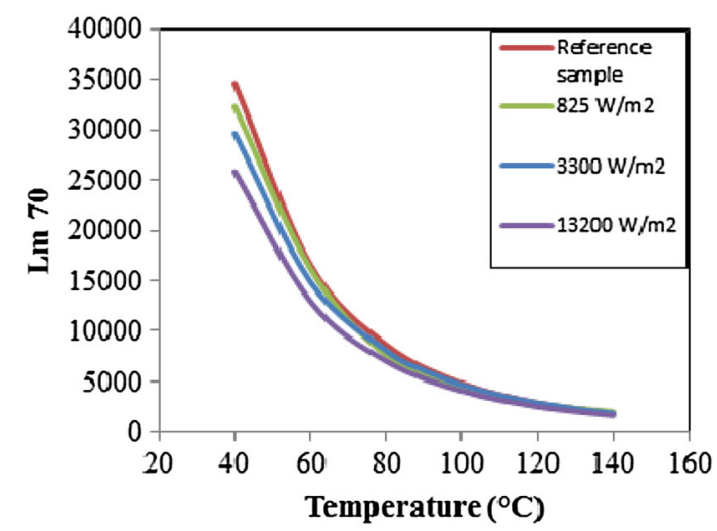

Fig. 10. Time-to-failure (70\% lumen decay) of remote phosphor at different temperatures for light intensities of $825 \mathrm{~W} / \mathrm{m}^{2}, 3300 \mathrm{~W} / \mathrm{m}^{2}$ and $13,200 \mathrm{~W} / \mathrm{m}^{2}$.

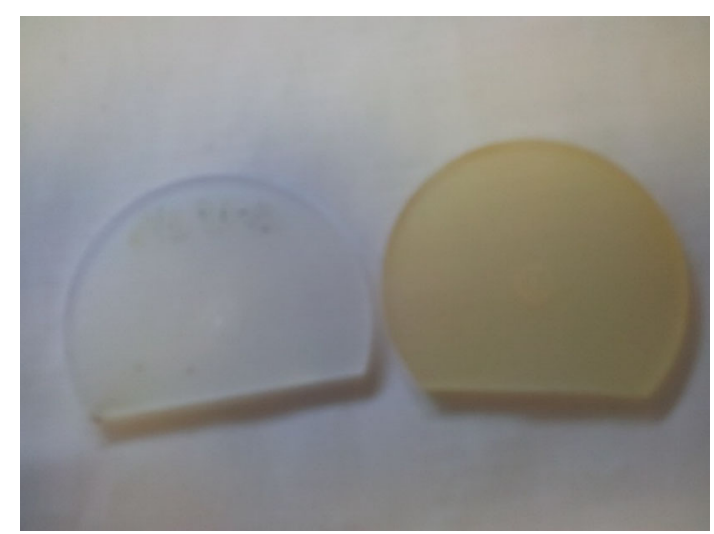

Fig. 11. Discoloration of BPA-PC after photo-thermal ageing at $140^{\circ} \mathrm{C}$.

bility. If the phosphor is placed away from the LED chip at a relatively large distance, which is called a remote phosphor configuration, the probability of light emitting from the phosphor and directly hitting the low-reflectivity LED chip becomes significantly lower, leading to a significant improvement in the phosphor efficiency. Besides, the remote phosphor configuration reduces the operating temperature of the phosphor, which is obviously expected to positively contribute to the reliability and the lifetime of white LEDs. Apart from the distance between the chip and the remote phosphor layer, thickness, concentration, ${ }^{4}$ geometry ${ }^{9}$ and packaging methods $^{10-13}$ of the phosphor layer also play important roles in determining the performance and the light quality of white LEDs. Among different types of phosphor, YAG:Ce is the most widely applied option in white light LEDs. ${ }^{18}$ However, the main disadvantage of the YAG:Ce is its relatively poor colour rendering index and severe thermal quenching of luminescence. Temperature is a very crucial parameter in the reliability of LEDs. High temperature levels can degrade the optical performance of the encapsulation and the lens. ${ }^{1-4}$ It has 
been already shown that thermal stress degrades the luminous output of the devices. ${ }^{15-23}$ This study aims at studying the effect of blue light intensity together with thermal stress on the lumen depreciation and the reliability of LED-based products and on the acceleration of optical degradation. The phosphor layer can itself be a heat generator as the input power increases and becomes more important if there is not a sufficient thermal path for heat dissipation. Thermal ageing of BPA-PC, which is widely used as a substrate in remote phosphor, is already studied. ${ }^{21}$ It has been found that BPA-PC in remote phosphor becomes more yellower than samples aged without phosphors under the radiation of light output. Figure 11 illustrates the darkening of BPA-PC under photo-thermal ageing at $120^{\circ} \mathrm{C}$. It is shown that the main reason for the ageing of BPA-PC is oxidation. By increasing the temperature and radiation of light, the rate of oxidation of BPA-PC would be increased, leading to the reduction of light output. ${ }^{21-23}$

The radiation of light increases the temperature of phosphor plates up to $20^{\circ} \mathrm{C}$ for the blue light radiation of $13,200 \mathrm{~W} / \mathrm{m}^{2}$. When the phosphor converts the short wavelength light (blue light) to the long wavelength light (yellow light), part of the blue light is converted to heat (phosphor conversion loss). Since in the remote phosphor configuration there is no thermal dissipation path around the phosphor layer, this generated heat increases the temperature of the phosphor. The heat generated at the phosphor layer is accumulated inside the layer and makes the temperature of the phosphor even higher than the test temperature. As a result, higher temperature causes faster degradation of the phosphor. Besides, thermal quenching of phosphors is another factor that has some influence on the degradation of phosphors and increases the kinetics of phosphor degradation. It is shown that the activation energy of the degradation reaction is $0.31 \pm 0.003 \mathrm{eV}$ (Fig. 3), depending on the stress levels. It is already reported ${ }^{18-21}$ that the proposed activation energy for remote phosphor plates has contributions from both the degradation of the substrate plates and the reduction in the phosphor conversion efficiency. ${ }^{20}$ One can see that by increasing the power of light, the temperature of the phosphor increases, leading to a larger depreciation rate (Fig. 2). The results also show that there is a direct relation between the temperature and the loss in conversion efficiency of the package. In fact, by increasing the ageing temperature, the conversion efficiency decreases. It is already reported ${ }^{20-23}$ that ageing of BPA-PC, used as substrate in remote phosphors, is faster than the phosphor itself. The decrease in the intensity of the blue light takes place with faster kinetics compared to that of the yellow peak, which is in agreement with the fact that there is a shift of the chromatic coordinates of the analyzed LEDs towards yellowish light. Our results show that the generalized Eyring equation can describe well the degradation kinetics of the remote phosphor component. In our specific configuration, the generalized Eyring parameters are found to be equal to $0.31 \mathrm{eV}\left(E_{\text {act }}\right)$ and $0.2(n)$.

\section{ACKNOWLEDGEMENTS}

This research was carried out under project number M71.9.10380 in the framework of the Research Program of the Materials Innovation Institute M2i (www.m2i.nl). The authors would like to thank M2i for funding this project. The authors would also like to acknowledge the "TNO innovation for life" company for SPD measurements.

\section{OPEN ACCESS}

This article is distributed under the terms of the Creative Commons Attribution 4.0 International License (http://creativecommons.org/licenses/by/4.0/), which permits unrestricted use, distribution, and reproduction in any medium, provided you give appropriate credit to the original author(s) and the source, provide a link to the Creative Commons license, and indicate if changes were made.

\section{REFERENCES}

1. S. Nakamura and G. Fasol, The Blue Laser Diodes, GaNm Based Light Emitters and Lasers (Berlin: Springer, 1997), p. 216.

2. E.F. Schubert, Light-Emitting Diodes (Cambridge: Cambridge University Press, 2003), p. 245.

3. P. Mottier, LEDs for Lighting Applications (New York: Wiley, 2009), p. 2.

4. R. Mueller-Mach and G.O. Mueller, Proc SPIE 3938, 30 (2000).

5. M.H. Chang, D. Das, P.V. Varde, and M. Pecht, Microelectron. Reliab. 52, 762 (2012).

6. R. Mueller-Mach, G.O. Mueller, M.R. Krames, and T. Trottier, IEEE J. Select. Topics Quant. Electron. 8, 339 (2002).

7. M. Yamada, T. Naitou, K. Izuno, H. Tamaki, Y. Murazaki, M. Kameshima, and T. Mukai, Jpn. J. Appl. Phys. 42, L20 (2003).

8. U.S. Department of Energy, Solid-State Lighting Research and Development, Multi-Year Program Plan. U.S. Department of Energy Report, Washington, DC (2013).

9. DOE Report Titles: LED Luminaire Lifetime, Recommendations for Testing and Reporting, 3rd ed.

10. Illuminating Engineering Society of North America, IES Approved Method for Measuring Lumen Maintenance of LED Light Sources. IES Report LM-80 08, New York, NY, (2008).

11. Luis.A. Escobar and William.Q. Meeker, Stat Sci 21, 552 (2006).

12. Illuminating Engineering Society of North America. Projecting Long Term Lumen Maintenance of LED Light Sources. IES Report TM-21 11, New York, NY, (2011).

13. M. Meneghini, L. Trevisanello, S. Podda, S. Buso, G. Spiazzi, G. Meneghesso, and E. Zanoni, Proc. SPIE. 633 (2006).

14. M. Meneghini, L. Trevisanello, C. Sanna, G. Mura, M. Vanzi, G. Meneghesso, and E. Zanoni, Microelectron. Reliab. 47, 1625 (2007).

15. N. Narendran, Y. Gu, J.P. Freyssinier, H. Yu, and L. Deng, J. Cryst. Growth 268, 449 (2004).

16. N. Narendran, Y. Gu, J.P. Freyssinier, and H. Yu, Phys. Status Solidi A 202, R60 (2005).

17. B.F. Fan, H. Wu, Y. Zhao, Y.L. Xian, and G. Wang, IEEE Photon. Technol. Lett. 19, 1121 (2007). 
18. M.D. Lago, M. Meneghini, N. Trivellin, G. Mura, M. Vanzi, G. Meneghesso, and E. Zanoni, Microelectron. Reliab. 52, 2164 (2012).

19. M.Y. Mehr, W.D. van Driel, K.M.B. Jansen, P. Deeben, and G.Q. Zhang, Microelectron. Reliab. 54, 138 (2014).

20. M.Y. Mehr, W.D. van Driel, and G.Q. Zhang, Microelectron. Reliab. 54, 1544 (2014).
21. M.Y. Mehr, W.D. van Driel, S. Koh, and G.Q. Zhang, Microelectron. Reliab. 54, 2440 (2014).

22. M.Y. Mehr, W.D. van Driel, H. Udono, and G.Q. Zhang, Surface aspects of discolouration in bisphenol A polycarbonate (BPA-PC). Opt. Mater. 37, 155 (2014).

23. M.Y. Mehr, W.D. Driel, K.M.B. Jansen, P. Deeben, M. Boutelje, and G.Q. Zhang, Opt. Mater. 35, 504 (2013). 